\title{
A bio-psycho-social model of successful aging as shown through the variable "physical activity"
}

\author{
Martina Kanning • Wolfgang Schlicht
}

Received: 25 May 2007 / Accepted: 22 July 2008 /Published online: 6 August 2008

(C) EGREPA 2008

\begin{abstract}
In this article, we present and explain a biopsycho-social model of successful aging with subjective well-being as a criterion of a successful aging process. We focus on physical activity because it is a crucial behavior. Physical activity can support successful aging in two different ways: first, due to its physiological and cognitive effects, and Second, an older person can enhance subjective well-being (SWB) while being physically active. The model points out that an older person can regulate SWB. To do this, an older person should set and pursue personally and culturally valued goals. The strength of the association between setting a goal and goal pursuance, respectively, and SWB depends on the extent a person is able to satisfy psychological needs (autonomy, competence, relatedness). But, the decision as to which goal will be set and pursued does not belong to the older person exclusively. The bio-psychosocial model explains that the chance to enhance SWB is restricted by personal dispositions (e.g., physiological constitution, psychological factors) and social-structural constraints (e.g., predominant stereotype of aging, facilities especially for target groups).
\end{abstract}

Keywords Aging $\cdot$ Model $\cdot$ Psychological . Physical activity. Psychosocial aspects

Funding credit: Landesstiftung Baden Württemberg gGmbH [Landesstiftung Foundation]

M. Kanning $(\bowtie) \cdot$ W. Schlicht

Institut für Sport- und Bewegungswissenschaft,

Department of Sport and Exercise Science, Universität Stuttgart,

Allmandring 2870569 Stuttgart, Germany

e-mail: martina.kanning@sport.uni-stuttgart.de

\section{Introduction}

Developed nations face a major challenge in the growing number of aging people. In 2002 Oeppen and Vaupel [41] predicted life expectancy to be continuously increasing. Life expectancy has steadily risen by 3 months per year for the last 160 years. The demographic progression in the developed nations requires a discussion about the growing number of aging people.

From a biological point of view, one may expect agerelated diseases, biological decline, and a loss of autonomy for most of the older people. Contrary to this worst-case scenario, elderly people report well-being and life satisfaction. Furthermore, they disagree with a negative perception of their aging process (in the corresponding literature, this phenomenon is known as the age invariance paradox) [61].

It seems to be insufficient to describe the aging process solely as a degree of physiological functioning. This perspective does not fit the age invariance paradox and over and above it would eliminate disabled people from a successful aging process. Conforming to this notion is a discussion about the predominant model of disease, which one can find in the corresponding scientific literature. Most often, disease is entailed by biological indices, only. This biomedical model leaves no room for social and psychological dimensions of illness. Those traditional biomedical view leads to the paradox effect that people with negative laboratory findings are feeling sick, while others are feeling well despite of diagnosed clinical symptoms (for details to multidimensional models of health and disease see [39, 52]).

Already in 1977, Engel [21] presented a bio-psychosocial model to provide a basis for understanding the determinants of disease. He claimed that "... a medical model must also take into account the patient, the social context in which he lives, and the complementary system 
devised by society to deal with the disruptive effects of illness...” (p. 196).

As for illness and disease, we need a more comprehensivewhat we call a bio-psychological-view, to explain what is meant by the term "successful aging." Up to now, successful aging has not been adequately explained because previous models fail to account for the concept of subjective perspectives of the elderly.

In developmental psychology, subjective well-being (SWB) defines one out of several significant criteria of successful aging. Therefore, successful aging is not only the effort to reduce age-related diseases; it is the effort to enhance SWB, to feel good, and to be satisfied with life despite physiological declines.

Among others, Diener et al. [17] stated that setting individually valued goals and having means to cope with stressful stimuli are both important for positive SWB. Ryan and Deci [48] pointed out that goals affect SWB if and only if someone is able to satisfy psychological needs while pursuing these goals. Psychological needs are basic needs like physiological ones. They refer to the motivational processes by which a person strives for autonomy and selfexpression within social contexts. Psychological needs are "an energizing state that, if satisfied, conduce [...] toward health and well-being but, if not satisfied, contribute [...] to pathology and ill-being" ([48], p. 74). Taken together, achieving SWB in older age is facilitated by setting and pursuing goals conducive to meeting personal psychological needs.

We assume that physical activity (PA) can support psychological need satisfaction in two different ways. First, several studies have shown that PA is followed by a variety of physiological and cognitive consequences (e.g., [36]). The physiological and psychological effects result in vitality and mobility, allowing an older person to live proactive and to set and pursue a larger variety of personal valued goals. Second, an older person can satisfy psychological needs directly while being active (e.g., self-respect).

Whether an older person will actually be active depends on a variety of determinants and life conditions. To predict advanced activities of daily living, Schlicht [53] suggested combining individual life circumstances, typical mindsets, and environmental conditions (see [37] as a meaningful study that combines individual, social, and physical/environmental influences to explain and predict PA).

As SWB is a key component or criterion for successful aging, we present a heuristic model to explain how to enhance SWB in order to age successfully (see Fig. 1). We point out that older people have the chance to influence their SWB by setting and pursuing personally and culturally valued goals satisfying their psychological needs. The main point of our model is the combination of physiological, psychological, and sociological factors as relevant influences on setting and pursuing personal valued goals. From this, it follows that the chance to enhance SWB is restricted by personal dispositions and social-structural constraints.

By explaining the structure of the bio-psycho-social model, we focus on PA. As mentioned above, PA is a crucial behavior for successful aging influencing the (successful) aging process in two different ways.

\section{Successful aging}

Different disciplines have been keeping busy assessing and describing the "success" of an aging process in great detail (for a review, see [32, 35]). However, an explicit definition of what is successful aging has not yet been readily accepted [5].
Fig. 1 Bio-psycho-social model of successful aging with subjective well-being as a criterion of a successful aging process

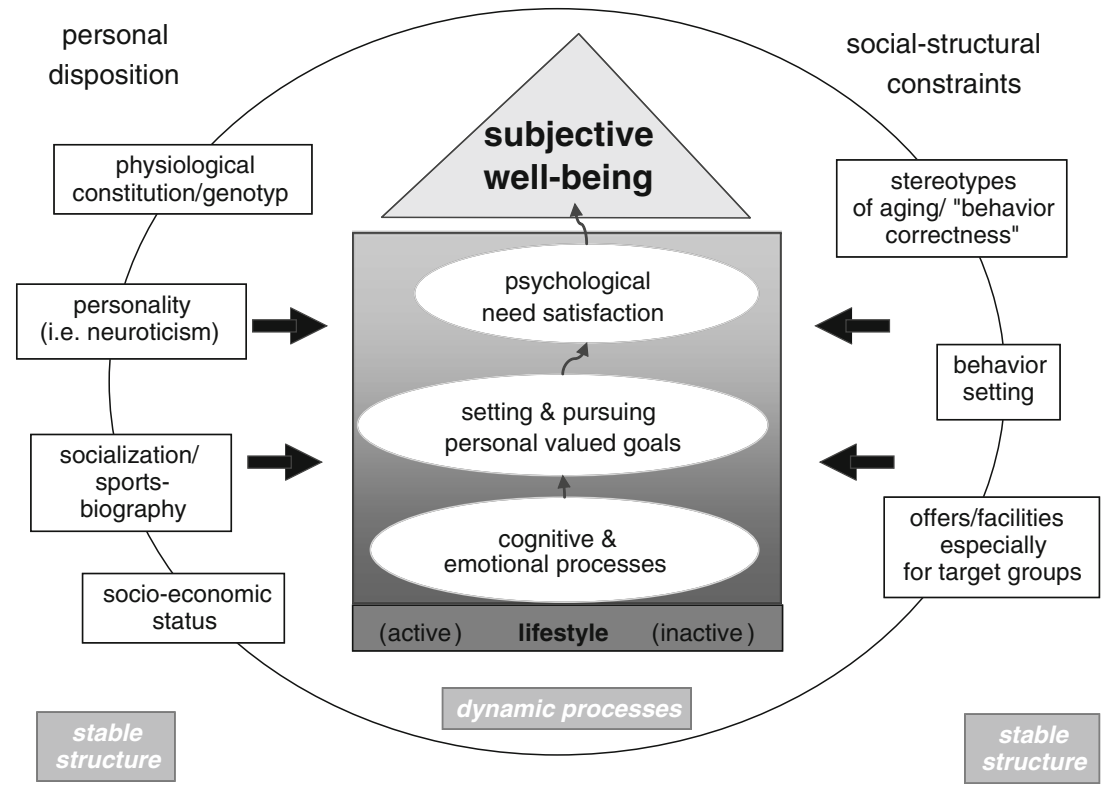


In a recent narrative review integrating 28 studies, Depp and Jeste [16] discovered 29 different definitions of successful aging. On average, one definition includes 2.6 different components (range=1-6). "Disability and/or physical functioning" are the components most frequently named $(90 \%)$. In $45 \%$ of the definitions, the amount of "cognitive functioning" is integrated, followed by "life satisfaction and SWB" (31\%), as well as by "social engagement" (28\%). The review emphasizes that it seems to be popular to describe successful aging mainly by physiological factors as well as cognitive and physical/ functional factors (see also [43]).

Rowe and Kahn [47] chose an analogical approach. Their definition of successful aging includes three key behaviors or characteristics which should be perpetuated as long as possible: (1) low risk of disease and disease-related disabilities, (2) high mental and physical functioning, and (3) active engagement with life. The authors described that although each factor is important in and of itself, they are also independent of each other. It is the combination of all three components that most extensively represents successful aging.

In our consideration, there is a close relationship between the possibility to engage actively in life and the other two characteristics. An older person in good shape is more likely to be able to be active in life. As is supported by abundant scientific evidence, PA lowers the risk of disease and contributes significantly to mental and physical functioning [36].

In addition to their attempts to define successful aging, Depp and Jeste [16] also designated determinants that influence successful aging. These determinants are as follows: young age, good health, and a healthy lifestyle (no smoking, exercise moderately and regularly).

Phelan et al. [42] explored how older persons define successful aging themselves. One thousand eight hundred ninety older American men and women $\left(M_{\mathrm{age}}=79\right.$ years) were contacted. The sample was primarily Caucasian and well educated. They mostly reported good self-rated health. Eighty percent to $90 \%$ of the sample felt independent in all their daily activities. The authors generated statements for the questionnaire of what successful aging might be. These were based on scientific conceptions and definitions of successful aging existing at present (e.g., [2, 26, 43, 49]). The sample rates the importance of these meanings on a three-point Likert scale with the anchors "important" and "not relevant." The sample's rating matches Rowe and Kahn's definition most closely [47]. According to this, successful aging should be described multidimensionally rather than unidimensionally (see also [8]). In addition to the three key factors, $75 \%$ of the older people also assess a psychological dimension to be important. This fourth dimension was surveyed with items like "feeling satisfied with my life the majority of time." Therefore, the older people maintain that physiological and functional aspects are important key components. Nevertheless, sociological and psychological needs must be satisfied too, if an older person experiences the aging process as to be successful.

Gatz and Zarit [26] pointed out that subjective perspectives of older persons are as important as objective measures concerning health or cognitive functioning. Subjective perspectives include SWB, life satisfaction, and evaluations of health or judgments about loneliness. From this point of view, subjective perspectives give the idea of "good old age" a psychological dimension. Defining successful aging without subjective perspectives will be an erroneous proceeding provoking incomplete results and disabling several groups in successfully aging (e.g., physically handicapped persons).

Due to Staudinger's argumentation [56], self-assessment and peer evaluation are not inevitably convergent. Against great odds (e.g., restrictions due to disease) most people feel happy (paradox of happiness) as one can see in the research of invulnerability or happiness (e.g., [61]). Therefore, it is important to analyze whether and to which extent older persons are satisfied with their actual lives.

We agree with Bowling and Dieppe [7] or other authors that successful aging should be described multidimensionally. These authors state that successful aging should be assessed continuously instead of dichotomously with the poles success or failure.

As mentioned above, in developmental psychology, SWB and life satisfaction are defined as one out of several important criteria for successful aging [24]. Life satisfaction is a category or dimension of SWB and refers to the evaluation of one's own life and life circumstances. It figures a balance between the "ought life" and the "real life." A high amount of life satisfaction will be reached if a person does not feel a significant difference between these two assessments.

Life satisfaction corresponds to the cognitive dimension of SWB, whereas positive and negative affects correspond to an affective dimension [6].

Moreover, SWB can be conceptualized as a "trait" and as an actual state oscillating around an individual set point [19]. So, the actual mood or affect (e.g., pleasure) has to be distinguished from general or habitual feelings (e.g., depressive or anxious mind). SWB as a "trait" shows more consistency in different types of situations (e.g., during work and during leisure time) and more stability across time.

To recapitulate what we have considered up until now, SWB is a significant criterion of successful aging. That means that older people age successfully if they feel well and if they are satisfied with their lives. By this and as to be seen in Fig. 1, we define SWB (including life satisfaction as well as positive and negative affects) as the criterion of successful aging. 


\section{Successful aging and need satisfaction}

Following the explanation above, the regulation of SWB is critical for successful aging. To enhance habitual SWB, an older person needs the opportunity to experience often positive affects and life satisfaction in daily life.

Diener et al. [17] gave a review including the last 30 years of research on SWB asking what the main influences on SWB are. Demographic variables like sex, age, marital status, and so on account for only $15 \%$ of the variance of SWB. Personality factors like neuroticism, hostility, or extraversion as well as tangible resources (like socioeconomic status) are further factors influencing SWB. Beyond the direct effects of both personal dispositions and tangible resources, a person is able to regulate SWB by setting and pursuing personally and culturally valued goals perseveringly [13, 17]. Those goals are specified by particular sociocultural contexts and/or by personal dispositions. Due to specific sociocultural backgrounds, valued goals change across a lifespan [23].

As Cantor et al. [13] stated, a person should select the "right" task at the "right" time. If a person lives the life he or she wants to live, SWB and life satisfaction will benefit the most (see also the construct of personal striving, e.g., [20]). Therefore, the strength of the association between participation in life and positive SWB depends on how far the chosen activity meets the wishes, wants, and ideals of the person (self-concordance). This level of self-concordance expresses to what extent a person decides in a selfdetermined manner and acts autonomously. The more a person has an "internal perceived locus of causality" ([49], p. 13) toward a goal and the more he or she is able to pursue that goal in a way that is valued intrinsically, the more her SWB will benefit. On the other hand, pursuing tasks that are intended to fulfill other people's desires and expectations (i.e., introjected regulation) do not have positive effects on SWB [55].

Ryan and Deci [48] described someone's desire to act autonomously and in a self-determined manner as one of three fundamental psychological needs. Feeling competent and related to others are the other two fundamental needs.

Sheldon and Elliot [54] analyzed the association between satisfied psychological needs and SWB in two longitudinal studies with 152 (first study) and 73 (second study) American students of psychology. At the beginning and at the end of the current semester, all students in the first study had to rate their SWB during the previous few days. Additionally, they rated their experiences of autonomy, competence, and relatedness in their daily lives during the past $24 \mathrm{~h}$ at the beginning of the current semester, as well as three times during it. According to the results of the first study, need satisfaction (autonomy, competence, relatedness) has significant and positive effects on positive SWB. In the second study, a more complex model is analyzed. In addition to the measurements of the first study, the second sample had to specify six personal goals (e.g., avoid conflicts with others, keep myself in good physical condition) that they wanted to pursue during the following semester. Furthermore, they rated how far they attained their personal goal eight times during the current semester. A structural equation model shows that goal attainment influences SWB. This effect is mediated by experiences of need satisfaction. In turn, this experience is influenced by the extent to which the goal meets the wishes, wants, and ideals of the person (selfconcordance). The analysis is conducted with a small sample size; however, it reaches an acceptable fit $\left(\chi^{2}=20.3\right.$ [9], goodness of fit index $=0.93$, comparative fit index $[\mathrm{CFI}]=0.93$ ).

Reis et al. [44] investigated the hypothesis that SWB is a direct outcome of the satisfaction of the three fundamental psychological needs. In their study, 76 students provided daily reports for 14 days. The authors used hierarchical linear modeling for their analyses with a data of measurement level (within persons) and a person level (between persons). Their findings support the relevance of the three fundamental psychological needs for SWB. For overall SWB, the between-person effect of feeling competent was significant $(B=0.108, t=2.0, p<0.05)$, whereas relatedness $(B=3.29, t=2.2, p<0.05)$ was associated significantly with positive affects.

Baltes et al. stated that everybody, even older people, have possibilities to reach personally and culturally valued goals. But, older people who suffer from diverse health problems (multimorbidity) usually reduce their daily activities and therefore miss the opportunities to reach those goals. For them, it might be very difficult to set and pursue a personal valued goal autonomously. In accordance to Baltes and Smith [3], they need a "strategy of managing the journey of aging into the oldest old." Baltes et al. have articulated and tested a model called Selective Optimization with Compensation (e.g., [2]). This model characterizes an effective life management strategy illustrating how to strive for specific goals: First, older people should select tasks which are individually important and fit their psycho-physical potentialities. For example, for an older person, it may not beneficial to set exercising goals similar to those of younger people. If an older person has only become acquainted with competitive sports and is no longer able to reach the required performance, the person should change these goals toward exercising for companionship and for the joy of the activity itself (see also primary and secondary control [28]). In addition to the selection of a specific task, a person should optimize his or her skills (i.e., make an effort) or should compensate favored behaviors (i.e., make a claim on someone). With growing age, compensation becomes more and more important [51]. Baltes [2] emphasized that a 
person will be able to age successfully if he or she arranges all three strategies in a clever and efficient manner. By this means, even the "oldest old" have the chance to age successfully [45].

Which goals a person prefers and strives for (selecting and optimizing) and which deficit will be compensated differ interindividually. As our model in Fig. 1 premises, it is crucial for SWB that the behaviors, which an older person wants to optimize, are self-concordant.

All in all, older people are able to manage their positive and negative affects and their life satisfaction - in short, their SWB. As Baltes showed, special competencies and coping strategies seem to be crucial in keeping the SWB positive [10].

\section{Exercise and its impact on successful aging}

Being in good shape is a relevant physiological factor influencing the setting and pursuing personally and culturally valued goals. PA can effect the constitution in a positive way. This has been demonstrated in a lot of studies. For example, moderate PA induces physiological and psychological effects (for physiological effects, see [38, 57]; for psychological, especially cognitive, effects, see $[36,60])$.

PA increases SWB, and PA supports older people in living without assistance as long as possible. An older person in good shape (physiological and cognitive) is able to participate in several leisure activities (e.g., visit a concert), and he or she can be involved with friends or family, for instance. In doing so, the opportunity increases to set and pursue personally and culturally valued goals with more variety (e.g., visiting a zoo with grandchild or inviting friends to play cards). For this, PA in our judgment is seen as a key behavior and as a precondition for successful aging [18]. PA fosters functional abilities referring to activities of daily living (e.g., dressing, eating, bathing), instrumental activities of daily living (e.g., shopping, housework, cooking), advanced activities of daily living (e.g., recreational activity, volunteer work), and mobility (e.g., walking, stair climbing).

Likewise, PA impacts SWB directly. A meta-analysis examined the effects of organized PA on SWB of older adults $\left(M_{\text {age }}=66.4, \mathrm{SD}=7.5\right)$ [40]. The analysis included 36 studies, and the authors calculated effect sizes representing the magnitude of the difference between pretest and posttest for treatment and for control groups, respectively. Physically active persons $\left(d_{\text {treatment }}^{\mathrm{c}}=0.24\right)$ show a greater increase in SWB then inactive persons $\left(d_{\text {control }}^{\mathrm{c}}=0.09\right)$.

Lee and Russell [31] analyzed the relationship between PA and SWB cross-sectionally and longitudinally. SWB was measured with the four mental health subscales of the Medical Outcomes Study Short Form (SF36). The sample of the cross-sectional study included 10,063 women between the age of 70 and 75. Higher levels of PA were associated with increased SWB even after the data had been adjusted for different confounders (marital status, body mass index, recent life events). A follow-up was made 3 years later. Now, data from 6,472 women were used in the longitudinal study. Comparing with women who remained inactive, women who started with PA (exercise adoption) or who maintained PA (maintenance group) showed an increase in SWB, whereas women canceling being physically active (cessation group) showed a significantly greater decrease in SWB (e.g., for the subscale social functioning: $M_{\text {change }}$ adoption $1.25, p<0.001, N=654 ; M_{\text {change }}$ maintenance $0.87, p<0.001, N=3,832 ; M_{\text {change }}$ cessation $-8.51, p<$ $0.01, N=1,103$; means were adjusted for values of the first measurement, marital status, body mass index, and recent life events).

Results of two German studies ILSE (Interdisciplinary and Longitudinal Study of Adulthood [46]) and Bonn Aging Study [15] emphasize that older people exercise in order to increase their fitness and their SWB.

American women up to 65 years intend nearly the same. They want to be fit, and they presume that a fit person can manage health problems more efficiently [34]. Again, 95\% of a sample $(n=409)$ of older Scottish people (65 to 84 years old) supposes that exercise supports health [14], and $79 \%$ of this sample believes devoutly that they do enough exercise to benefit from the anticipated healthenhancing effects of PA.

But, the matter of fact is that more than half of the people exercise less than $2 \mathrm{~h}$ per week with moderate intensity. For the remaining time, they prefer playing cards or meeting friends, or they volunteer for church activities.

The abovementioned studies demonstrate the positive impact of PA, and they clarify that older people do not expect to feel well and happy exclusively while being active. There are interindividual differences among older people as to which behaviors make them feel well. PA can produce good feelings like acceptance, competence, and relatedness (cf. fundamental psychological needs). But, a person must believe devoutly in PA as a supporting practice. So, it depends on internal and external influences, whether an older person prefers an active or sedentary lifestyle.

\section{Psychological and social-structural influences on older people's decision as to which goal will be set and pursued}

In a cross-sectional study, Salman et al. [50] analyzed several factors possibly influencing the decision as to what kind of activities someone prefers during leisure time. The 
authors use the behavioral choice theory sensu Epstein [22] including explicitly both individual and environmental influences to explain and predict behavioral choices. They performed multiple linear regression analyses to determine the overall variance in PA explained by the following three barriers: (1) psychological (e.g., feeling tired) and environmental barriers (e.g., cost), (2) fun and enjoyment while being active or inactive, and (3) the individual preference to choose an active or an inactive spare-time job. Data from 1,332 men and women ( $M_{\text {age }}=45$ years) were analyzed. All three factors are associated significantly with being active during leisure time (fit of the model: $\chi^{2}(8)=10.8, p=0.212$; feeling tired: odds ratio $[\mathrm{OR}]=0.5,95 \%$ confidence interval $[\mathrm{CI}]=0.4,0.8, p<0.001$; cost: $\mathrm{OR}=1.5,95 \% \mathrm{CI}=1.1,2.1$, $p=0.009$; enjoy $\mathrm{PA}: \mathrm{OR}=1.8,95 \% \mathrm{CI}=1.4,2.5, p<0.001$; prefer moderate $\mathrm{PA}: \mathrm{OR}=1.9,95 \% \mathrm{CI}=1.4,2.6, p<0.001)$. Therefore, the kind of activity a person prefers does not depend on perceived psychological and environmental barriers only. Individual preferences and perceived fun and enjoyment during exercise are also important for the decision to be physically active or inactive during leisure time.

As our model in Fig. 1 describes, the decision whether an older person chooses and pursues a physically active lifestyle depends on cognitive (like self-efficacy or attitudes) and emotional processes concerning those activities.

The results of leastwise one prospective cohort study with 1,725 persons older than 50 years $\left(M_{\mathrm{age}}=60.9\right.$; $\mathrm{SD}=$ 8.2) show that positive attitudes about exercising have an important influence. First, positive attitudes influence the intention to participate in an exercise program, and second, they have an impact on the actual rate of participation [58]. The authors asked subjects at baseline and 6 months later. The subjects took part in one of ten different activity programs designed especially for older persons (e.g., calisthenics, fitness, walking). The stepwise logistic regression analysis identified proactive attitudes $(\mathrm{OR}=1.9 ; 75 \%$ $\mathrm{CI}=1.2,3.0)$ and the intention to participate $(\mathrm{OR}=3.9 ; \mathrm{CI}=$ 2.0, 7.6) as significant predictors for regular participation. Proactive attitudes $(\mathrm{OR}=3.30 ; \mathrm{CI}=1.73,6.31)$ were a predictor for intention, too. The determinants for taking part in an exercise program were based on two behavioral models, the theory of planned behavior [1] and social learning theory [4].

Social-cognitive models mention certain predictors with a specific conjunction among them. Each model allows describing, explaining, and predicting the behavior change process. The main purpose of these models is to explain behavior, especially behavior change from risk behavior, like smoking or inactivity, to health-enhancing behavior (quitting smoking, being active). The predictors are cognitive processes. In addition to intention and attitude, they include self-efficacy and outcome expectancies, for instance.
These models presume that the decision to be active depends on internal factors like attitudes, motives, and interests (for the area of sports biography, see the review [25]). However, the decisions for being active are not only an expression of willingness (cognitive effort). They are determined by social constraints and environmental causes, and by this, they are somewhat unconscious or not reflected. Thus, sociological and cultural living conditions, as well as adequate opportunities and offers, influence the psychological entities (see Fig. 1).

McNeill et al. [37] tested different pathways by which social cognitive and ecological factors influence PA. They analyzed social environmental variables like informational and emotional social support, physical environmental variables like quality and availability of PA facilities, and individual variables like motivation and self-efficacy. Nine hundred ten adults $\left(M_{\mathrm{age}}=33, \mathrm{SD}=13.1\right)$ completed a selfadministered survey. Structural equation modeling was used for analyzing, and the results show that both the social and the physical environments had indirect effects on PA. The effect was mediated through motivation and self-efficacy (for moderate PA: $\chi^{2}=1,969.5$ [677]; $\mathrm{CFI}=0.93$; root mean square error of approximation [RMSEA] $=0.046$ ).

Nowadays a 60 -year-old person shows more readiness to exercise than some decades before. Furthermore, older people, especially female, are in fact more active today than older women 20 years before [12]. Breuer [11] explained this alteration with higher motivation of older people to keep healthy. A second reason may be a modified view of what is prototypic for an older person today and what older persons are expected to do. Those normative beliefs and culturally learned ideas form special stereotypes of aging influencing behavior of older people [9]. A few years ago, older people lived in accordance with the predominant stereotype of aging when they exercised only due to therapeutic or rehabilitative reasons. Today, higher age is no longer connected inevitably with inactivity. Older people who are active are not only accepted; they even form today's ideal. Thus, the social environment forms a special structure of thoughts and expectancies which we will call "behavior correctness" (cf. Fig. 1).

In addition to the impact of normative beliefs, typical behavior settings also influence an individual's action. In the concept of behavior setting, Barker emphasized interindividually equal behavior in specific situations (for a review, see [30]). Kaminsky ([30], p. 13) gave colorful examples: People in a bread shop behave like someone needing bread, and most people are convinced that a dancing school is not the right place for worship, and so on ([30], p. 34). So, in a behavior setting, the behavior of different people shows no significant interindividual difference. The concept of behavior setting describes an existing close fit between typical behavior patterns and 
corresponding environmental situations (synomorphe connection). In these (typical) situations, people usually do not behave like they want; they behave like the situation "forces" them to. Behavior settings are some kind of a socio-physiological environment dictating the individual's behavior.

As a concrete example, the impact of given facilities for exercising on the rate of activity is analyzed by $\mathrm{Li}$ et al. [33] in their longitudinal study. During 1 year, they interviewed 303 American women and men every third month. On the average, the sample was 74 years old $\left(\mathrm{SD}_{\mathrm{age}}=6.24\right)$ and lived in 28 different municipalities. The authors used multilevel modeling to investigate between-neighborhood and within-neighborhood variability in walking activity. The model yielded a reasonably good fit to the data $\left(\chi^{2}=51.71\right.$ [27], $p=0.003$; RMSEA=0.05). Due to the results of the between-neighborhood analysis, social cohesion of the neighborhood was significantly related to the amount of walking activities at baseline $(\beta=0.62)$ showing that neighborhoods with high levels of social cohesion were associated with greater levels of walking activity at baseline. The presumed safety of relevant paths for walking $(\beta=0.44)$ and easy access to other facilities for exercising $(\beta=0.61)$ are significant predictors of a lower decline of walking activity during the survey period.

Breuer [11] compared the self-reported activity rate of people who are living in a rural area with the activity rate of people who are living in an urban area. According to his results, people, living in the rural area, are more active than people, living in the city. But, above the 60th birthday, the proportion changed. With this age, people who are living in an urban area are most active now. Breuer [11] stated that especially older people may find adequate activities more often in an urban than in a rural area. As an alternative interpretation, we guess that the anonymity of the city makes it easier for older people to be active.

An interesting result is the proportion of active men to active women above the 70th birthday. In the rural area, men were more active than women $(\operatorname{men}=42 \%$ vs. women= $33 \%$ ), whereas in the urban area, women show a more active lifestyle (women $=41 \%$ vs. men $=35 \%$ ). Again, it may be that the tradition-based behavior correctness concerning activity is stronger in the rural area than in the city.

All in all, it seems that the predominate stereotype of aging, special behavior settings, and given facilities form a social and physical environment that hinder or facilitate an active lifestyle of older people (see Fig. 1).

But, neither the physical nor the social environment influences someone's activity rate in a unidirectional manner. Personal ideas and wishes (concerning exercise) depend on how a person examines his or her social and physical environment. Thus, the process of socialization toward an active lifestyle is an interactive process with an active human in focus.
The model in Fig. 1 suggests that an individual's socialization and experiences with exercise (sports biography) influence cognitive and emotional factors concerning exercise. Again, these social-structural and psychological factors have an impact on older people's decision whether exercise is worthwhile to be chosen as a component of their lifestyle. A physically active person can influence his or her constitution so that personally and culturally valued goals can be set and pursued with more variety (physiological factor). Therewith, social-structural, psychological, and physiological factors have an influence on SWB and with it on the chance to age successfully.

\section{Concluding remarks}

We introduce a heuristic model explaining successful aging as a process (see Fig. 1). In doing this, we focus on PA. PA proves to be a crucial behavior because of its two different roles in the successful aging process. First, it causes physiological and cognitive effects: An older person in good shape has the opportunity to set and pursue a greater variety of personal goals. Second, an older person can satisfy psychological needs directly while being physically active.

We conclude that everybody has the chance to age successfully when he or she manages to do something on his or her own initiative. To enhance SWB, it seems to be highly important that a (older) person considers which tasks or goals could satisfy psychological needs. To achieve this satisfaction, the person should know whether all of these needs are being continually satisfied or, for example, whether one is being neglected. For instance, after a person has gone into retirement, he or she may feel unhappy, somewhat depressed, and superfluously. It seems likely that this person misses the feeling of competence and therefore should look for tasks or goals satisfying the psychological need for competence. Maybe, the person will learn a new language or study history at the university.

Second, we point out that the decision as to which goal will be set and pursued is not made by the older person exclusively. The decision to be physically active, for instance, depends on social-cognitive (e.g., self-efficacy, attitude) and emotional factors toward exercise. These factors, in turn, are influenced by social-structural constraints (e.g., facilities for exercise especially for older persons) and personal dispositions (e.g., sports biography).

The heuristic model presented in Fig. 1 is a holistic approach in the sense that it includes physiological (e.g., constitution), psychological (e.g., social-cognitive determinants), and sociological (e.g., stereotype of aging) aspects to explain successful aging. As such, the model agrees with the recommendations of developmental psychology that an 
aging process is dependent upon different factors and should be explained multidimensionally rather than unidimensionally [29].

Likewise, Lehr [32] presented a model postulating an impact of psychological and physiological factors on longevity. Furthermore, emotional and cognitive (psychological) factors were influenced by individual socialization and environmental factors. The model is, however, very complex so that it is not revisable (cf. [59]). Additionally, Lehr [32] used longevity as a criterion, which does not include subjective perspectives of one's aging process.

Although individual parts of our bio-psycho-social model are well founded, more studies are needed to confirm the assumptions of the heuristic model as a whole. For example, it is not clear whether the impact of socialstructural constraints is as powerful as the impact of personal dispositions. Furthermore, we do not know if this relation is transferable to older people in general. Because of differing biographies and diverse impacts of life changes, older people show high interindividual variability. For instance, some older people may not care about predominant stereotypes of aging or about existent exercise facilities as they live in anonymous urban surroundings and prefer exercising on their own (e.g., walking). For these older people, social-structural constraints hardly influence their decision to be physically active.

\section{References}

1. Ajzen I, Madden TJ (1986) Prediction of goal directed behaviour: attitudes, intentions, and perceived behavioral control. J Exp Soc Psychol 22:453-474

2. Baltes PB (1997) On the incomplete architecture of human ontogeny: selection, optimization, and compensation as foundation of developmental theory. Am Psychol 52:366-380

3. Baltes PB, Smith J (2003) New frontiers in the future of aging: from successful aging to the young old to the dilemmas of the fourth age. Gerontology (Behav Sci) 49:123-135

4. Bandura A (1977) Self-efficacy: toward a unifying theory of behavioral change. Psychol Rev 84:191-215

5. Blazer DG (2006) Successful aging. Am J Geriatr Psychiatry 13 (1):2-5

6. Böhmer S, Ravens-Sieberer U (2005) Das konzept der lebensqualität in der gesundheitsbezogenen forschung. In: Schwarzer R (ed) Gesundheitspsychologie (Bd 1 der Enzyklopädie der Psychologie). Hogrefe, Göttingen, pp S369-S389

7. Bowling A, Dieppe P (2006) What is successful ageing and who should define it. BMJ 331:1548-1551

8. Bowling A, Iliffe S (2006) Which model of successful ageing should be used? Baseline findings from a British longitudinal survey of ageing. Age Ageing 35:607-614

9. Brandtstädter J (1990) Entwicklung im lebenslauf. Ansätze und probleme der lebenspannen-entwicklungspsychologie. In: Mayer KU (ed) Lebensverläufe und sozialer Wandel. Kölner zeitschrift für soziologie und sozialpsychologie, sonderheft, 31. Westdeutscher, Opladen, pp S322-S350
10. Brandtstädter J, Rothermund K (1998) Bewältigungspotentiale im höheren alter: adaptive und protektive prozesse. In: Kruse A (ed) Psychosoziale gerontologie (Bd 1 grundlagen). Hogrefe, Göttingen, pp S223-S237

11. Breuer C (2002) Sozialer wandel und sportengagement im lebenslauf. In: Allmer H (ed) Sportengagement im lebenslauf (Bd. 23). Academica, Sankt Augustin, pp S61-S82

12. Breuer C (2004) Zur dynamik der sportnachfrage im lebenslaufdynamics of life-span demand for sport. Sport und GesellschaftSport and Society 1:50-72

13. Cantor N, Sanderson CA (2003) Life task participation and wellbeing: the importance of taking part in daily life. In: Kahneman D, Diener E, Schwarz N (eds) Well-being: the foundation of hedonic psychology. Russel Sage Foundation, New York, pp 230-243

14. Crombie IK, Irvine L, Williams B, McGinnis AR, Slane PW, Alder EM, McMurdo MET (2004) Why older people do not participate in leisure time physical activity: a survey of activity levels, beliefs and deterrents. Age Ageing 33(3):287-292

15. Denk H (1997) Health, the main motivation for physical activities of the elderly? In: Huber G (ed) Healthy, aging, activity and sports. Health Promotion, Wertbach-Gamburg, pp 394-399

16. Depp CA, Jeste DV (2006) Definitions and predictors of successful aging: a comprehensive review of larger quantitative studies. Am J Geriatr Psychiatry 13(1):6-20

17. Diener E, Suh EM, Luca RE, Smith HL (1999) Subjective wellbeing: three decades of progress. Psychol Bull 125(2):276-302

18. DiPietro L (2007) Physical activity, fitness, and aging. In: Bouchard C, Blair SN, Haskell WL (eds) Physical activity and health. Human Kinetics, Champaign IL, pp 271-285

19. Eid M, Diener E (2004) Global judgment of subjective wellbeing: situational variability and long-term stability. Soc Indic Res 65:254-277

20. Emmons RA (1996) Striving and feeling-personal goals and subjective well-being. In: Gollwitzer PM, Baragh JA (eds) The psychology of action. Guilford, New York, pp 313-337

21. Engel GL (1977) The need for a new medical model: a challenge for biomedicine. Science 196(No. 4286):129-136

22. Epstein LH (1998) Integrating theoretical approaches to promote physical activity. Am J Prev Med 15(4):257-265

23. Erikson EH (1950) Childhood and society. Norton, New York

24. Ferring D, Filipp SH (1997) Retrospektive bewertung des eigenen lebens: der lebenszufriedenheits-graph. Z Entwicklungspsychol Padagog Psychol 29(1):83-95

25. Frogner E (1991) Sport im lebenslauf. eine verhaltensanalyse im breiten- und freizeitsport. In: Baier H, Klages H, Schäfer B, Tenbruck FH (eds) Soziologische gegenwartsfragen. Enke, Stuttgart, p 50

26. Gatz M, Zarit SH (1999) A good old age: paradox or possibility. In: Bengtson VL, Schaie KW (eds) Handbook of theories of aging. Springer, New York, pp 396-416

27. Havighurst RJ (1963) Successful aging. In: Williams RW, Tibbitts C, Donahue W (eds) Processes of aging. vol. 1. Atherton, New York, pp 299-320

28. Heckhausen J, Schulz R (1998) Development and regulation in adulthood: selection and compensation via primary and secondary control. In: Heckhausen J, Dweck CS (eds) Motivation and selfregulation across the life-span. Cambridge University Press, New York, pp 50-77

29. Inui TS (2003) The need for an integrated biopsychosocial approach to research on successful aging. Ann Int Med 139(Suppl):391-394

30. Kaminski G (1986) Ordnung und variabilität im alltagsgeschehen. Hogrefe, Göttingen

31. Lee C, Russell A (2003) Effects of physical activity on emotional well-being among older Australian women-cross-sectional and longitudinal analyses. J Psychosom Res 54:155-160

32. Lehr U (2000) Psychologie des alterns, 9th edn. Quelle \& Meyer, Wiebelsheim 
33. Li F, Fisher KJ, Brownson RC (2005) A multilevel analysis of change in neighborhood walking activity in older adults. J Aging Phys Act 13:145-159

34. Lucas JA, Orshan SA, Cook F (2000) Determinants of healthpromoting behavior among women ages 65 and above living in the community. Sch Inq Nurs Pract 14(1):77-100

35. Lupien SJ, Wan N (2004) Successful aging: from cell to self. Philos Trans R Soc Lond B Biol Sci 359:1413-1426

36. McAuley E, Kramer AK, Colcombe SJ (2004) Cardiovascular fitness and neurocognitive function in older adults: a brief review. Brain Behav Immun 18:214-220

37. McNeill LH, Wyrwich KW, Brownson RC, Clark EM, Kreuter MW (2006) Individual, social environmental, and physical environmental influences on physical activity among black and white adults: a structural equation analysis. Ann Behav Med 31(1):36-44

38. Meusel H (2004) Bewegung und sport. In: Kruse A, Martin M (eds) Enzyklopädie der gerontologie. Huber, Göttingen, pp S255-S272

39. Myrtek M (1998) Gesunde kranke — kranke gesunde: psychologie des krankheitsverhalten, 1st edn. Huber, Bern

40. Netz Y, Wu M-J, Becker BJ, Tenebaum G (2005) Physical activity and psychological well-being in advanced age: a meta-analysis of intervention studies. Psychol Aging 20:272-284

41. Oeppen J, Vaupel JW (2002) Broken limits to life expectancy. Science 296:1029-1031

42. Phelan EA, Anderson LA, LaCroix AZ, Larson EB (2004) Older adults' view of "successful aging"- - how do they compare with researchers' definition. Am J Geriatr Psychiatry 52:211-216

43. Phelan EA, Larson EB (2002) "Successful aging"-where next? Am J Geriatr Psychiatry 50:1306-1308

44. Reis HT, Sheldon KM, Gable SL, Roscoe J, Ryan RM (2000) Daily well-being: the role of autonomy, competence, and relatedness. Pers Soc Psychol Rev 26:419-435

45. Riedinger M, Freund A, Baltes PB (2005) Managing life through personal goals: intergoal facilitation and intensity of goal pursuit in younger and older adult. J Gerontol 60B(2):P84-P91

46. Roether D, Vogt M (2003) Freizeitsport-ein aktiver beitrag für wohlbefinden und gesundheit im alter. In: Eisfeld K, Wiesmann U, Honnich HJ, Hirtz P (eds) Gesund und bewegt ins alter. AFRA, Butzbach-Griedel, pp S126-S136

47. Rowe JW, Kahn RL (1998) Successful aging. Dell (Trade), New York
48. Ryan RM, Deci EL (2000) Self-determination theory and the facilitation of intrinsic motivation, social development, and wellbeing. Am Psychol 55(1):68-78

49. Ryan RM, Sheldon KM, Kasser T, Deci EL (1996) All goals are not created equal - an organismics perspective on the nature of goals and their regulation. In: Gollwitzer PM, Baragh JA (eds) The psychology of action. Guilford, New York, pp 7-26

50. Salmon J, Owen N, Crawford D, Bauman A, Sallis JF (2003) Physical activity and sedentary behavior: a population-based study of barriers, enjoyment, and preference. Health Psychol 22(2):178-188

51. Schlicht W (2000) Gesundheitsverhalten im alltag: auf der suche nach einem paradigma. Z Gesundh Psychol 8(2):49-60

52. Schmidt L (1998) Zur Dimensionalität von gesundheit (und krankheit). Z Gesundh Psychol 6:161-178

53. Schulz R, Heckhausen JA (1996) A life span model of successful aging. Am Psychol 51:702-714

54. Sheldon KM, Elliot AJ (2005) Goal striving, need satisfaction, and longitudinal well-being: the self-concordance model. J Pers Soc Psychol 76(3):482-497

55. Sheldon KM, Kasser T (1995) Coherence and congruence: two aspects of personality integration. J Pers Soc Psychol 68:531-543

56. Staudinger UM (2000) Viele gründe sprechen dagegen und trotzdem geht es vielen Menschen gut: das paradox des subjektiven Wohlbefindens. Psychol Rundsch 51(4):185-197

57. Stewart KJ (2005) Physical activity and aging. Ann NY Acad Sci 1055:193-206

58. Stiggelbout M, Hopman-Rock M, Crone M, Lechner L, van Mechelen W (2006) Predicting older adults' maintenance in exercise participation using an integrated social psychological model. Health Educ Res 21(1):1-14

59. Stiller J, Alfermann D (2003) Sind aktivere auch die gesünderen? - die beziehung zwischen freizeitaktivitäten und subjektiver gesundheit im höheren Lebensalter. In: Eisfeld K, Wiesmann U, Honnich HJ, Hirtz P (eds) Gesund und bewegt ins alter. AFRA, Butzbach-Griedel, pp S165-S171

60. Vance DE, Wadley VG, Ball KK, Roenker DL, Rizzo M (2005) The effects of physical activity and sedentary behavior on cognitive health in older adults. J Aging Phys Act 13:294-313

61. Whitbourne SK (2001) Adult development and agingbiopsychosocial perspectives, 2nd edn. Wiley, Hoboken, NY 